\title{
The Effect of Computerized Educational Software on the Achievement of the Third Grade Students in Learning Arabic in Jordan
}

\author{
Lina Talal Al-Adwan ${ }^{1}$ \\ ${ }^{1}$ The Ministry of Education, Jordan \\ Correspondence: Lina Talal Al-Adwan, he Ministry of Education, Jordan. E-mail: m.alzboon@yahoo.com
}

Received: September 12, 2019

Accepted: September 26, 2019

Online Published: September 27, 2019

doi:10.5539/mas.v13n10p126

URL: https://doi.org/10.5539/mas.v13n10p126

\begin{abstract}
This study aimed to reveal the impact of computerized educational software on the achievement of third grade students in learning Arabic language in Jordan. To achieve the objective of this study, the researcher built a computerized educational software, and an achievement test that measures reading and writing skills of third grade students. The validity and reliability of the study tools have been verified. The study members consisted of (50) male and female students of the third grade students in the first semester 2018/2019, were distributed into two groups, one of which is an experimental group of (25) male and the other officer is composed of (25) male and female students. He divided the sample into two groups: a control officer studied in the usual way, and an experimental study using computerized educational software.

The results showed that there were statistically significant differences at the level of significance $(\alpha=0.05)$ in the achievement of the third grade students in the Arabic language (reading and writing) in favor of teaching method using computerized educational software.

The study recommended: generalizing the experience of the use of computerized educational software that was applied to the students of Arabic language on different subjects, taking advantage of the positive impact of the use of computerized educational software in the achievement of students, conducting new studies with different designs and measurement tools to examine the impact of the use of computerized educational software in materials. A variety of different levels of study.
\end{abstract}

Keywords: computerized educational software, reading, writing

\section{Introduction}

Scientists are constantly looking for the best ways to provide an interactive learning environment that attracts the attention of students. The computer and the Internet are among the most successful means to provide this rich environment.

Many educators have placed great hopes on the role that computers and the Internet can play if they are well used in the educational learning process. Many studies have indicated that the use of computers improves the quality of education and increases its effectiveness and provides opportunities for sensory experiences that are closer to real experiences, thus providing deeper and greater learning effect, arousing the interest of students and satisfying their needs., And raises their self-activity and provides a psychological educational environment appropriate for them and thus helps to grow concepts and the formation of scientific trends desired (Ashtiyou and Olayan, 2010).

The Jordanian leadership has recognized the need to establish a knowledge-based learning system based on modern technologies to improve education. Accordingly, the e-learning strategy has been adopted. To provide schools with computers and training courses for teachers to use modern communication and information technologies and learning methods. Thus, the Hashemite Kingdom of Jordan has moved to a learning system that relies on learning ability. M. Self and critical thinking rather than the traditional system (Qasim and Muhammad, 2009).

In light of this progress and rapid scientific and technological development, educational institutions have reconsidered their objectives and practices. 2015). 
Reform and development of education has become a national priority in many countries of the world. Efforts to reform scientific education have emphasized the future, the development of scientific culture, the capacity of scientific investigation, technological design, problem solving skills and decision-making ability. Education reform movements are based on the assumption that the new vision of education requires significant changes in the educational system because of its vulnerability. Which defines the role of the teacher and facilitator and supporter and the role of the learner researcher, and directed towards modern teaching strategies based on the use of information technology and multimedia in science curricula, in the light of the technological revolution and scientific culture has become the technology of education inevitable In their employment, integration and activation in the science curriculum and teaching strategies so that educational reform movements pay off (Zaytoun, 2010).

Education aims to achieve positive changes desirable for students who are on the seats of study, is to acquire the basic concepts and skills in life for tomorrow belonging to them, and in order for students to be able to live life in all its requirements and challenges should pay attention to the intellectual aspect and skills of problem-solving and social communication (Zeitoun, 2008 ).

Information technology is represented by the computer and the Internet and the subsequent multimedia of the most successful means to provide a rich learning environment learning (Enezi, 2011), and computer is the top of what produced by technology, has entered in all walks of life, including education, and has received the most attention from Among the modern technologies in the field of education; because of its educational advantages and capabilities of improving the quality of education and increasing its effectiveness, and provide an opportunity to bring sensory experiences closer to real experiences, and provide deeper and greater learning and longer impact, and stir students' interests and hobbies They are used to help develop concepts and form the desired scientific trends, simplify and clarify information and ideas and help students to perform the required skills as it provides the possibility of presentation by sound, image, movement and drawing. The field of use in the educational process of learning, and thus computer is a distinct technology that allows to achieve great effectiveness of education through communication and interaction between the teaching material and the learner (Ashtiyou and Olayan, 2010).

The introduction of computer and ICT in the classroom has improved the relationship between the teacher and the learner, and the development of knowledge sources from books to software. Several studies have shown that the use of computers in the process of learning and teaching is very effective in developing students' ability to think and interact and stimulate their motivation towards learning (Hassan, 2016).

In the Hashemite Kingdom of Jordan, the Ministry of Education pays great attention to preparing and qualifying students for future life. In 2002, the Education Forum was held in the Future Jordan with the participation of relevant sectors and a group of international experts. The Forum was held as a center for information technology and the promotion of the national economy based on Knowledge and to rebuild the educational system in Jordan.

His Majesty King Abdullah II Bin Al-Hussein has taken the royal message on the development of the higher education sector in 2003 as a pledge to strengthen the power of ICT centers. The Ministry of Education has adopted this vision by embodying it on the ground by finding computers in all its schools. Training courses for technical and teaching cadres, thus making ICT an indispensable means of survival in an open world based on competitiveness as a criterion for progress and prosperity, and the education system emerges as the most important engine to bring about the desired change in life style. And thinking (Al-Zoubi, 2010).

In 2003, the Jordan Education Initiative was launched, which aims to achieve educational reform through the adoption of information and communication technologies. This initiative included the development and application of curricula in the field of e-learning in 100 experimental exploration schools. As part of the Computerization of Education Project in Jordan, six curricula have been computerized and the Education Development Initiative has been launched towards the knowledge economy with the aim of upgrading the educational system in Jordan to cope with local and lesser needs and needs. Scientific and International (Leddawi 2010).

Minhaj Company has developed computerized educational materials that are fully linked to the official curriculum in schools with a difference in the way of presentation that is characterized by a great deal of interaction between the student and the software. This software has been developed to cover all materials and curricula approved by the Ministry of Education for all stages taking into account International standards and standards adopted in the process of computerizing educational materials technically and educationally so that they contained a full explanation of the lesson, interactive questions in the form of educational games, tests and worksheets (Shboul and Olayan, 2014). 
To achieve easy access to the computerized curriculum, the Ministry of Education implemented two projects: the establishment of the Queen Rania Al Abdullah Center for Information Technology and the introduction of the content of the computerized curriculum on the e-learning system on the portal of the Queen Rania Center for Information Technology.

The Ministry of Education has started using the e-learning system (EduWave), which is one of the technological means of communication in the educational communication process, as the use of technological media contributes to raise the level of learning and teaching, and to break the deadlock based on indoctrination and save information to the vitality of learning Exploration, research and analysis to solve problems. The IDEV system has become the most prominent e-learning projects adopted by the Ministry. Its adoption has led to a change in the role of both the teacher and the learner. The teacher became mentor, mentor, facilitator and supervisor of the educational learning process. The e-curriculum communicates information in a way that encourages the student to fully understand the scientific content in addition to increasing the scientific information in the required field through access to the resources provided by the Ministry of Education (Abu Hassan, 2007).

Thus, the use of educational materials programmed in the educational sector has led to great success in various subjects and can be used alone or with another educational strategy. A program written in the method of programmed instruction can be used to teach a course with a word or a part of it. When used as an extra activity, it is also found that it can provide students with additional learning experiences and improve their abilities. The teacher cannot provide them due to lack of time in the classroom, and the teaching materials have proved their effectiveness in teaching. He continues to study according to his own pace and provides him with continuous feedback and provides appropriate reinforcement (Mahasneh, 2015).

Most scientists, such as Cody Bonn and Calton, agree that education for thinking is an important goal of education, so that universities should provide students with thinking opportunities and prioritize them as an educational goal in order to be able to deal effectively with complex life problems (Nashwati, 2010).

There is no doubt that these changes and developments have repercussions on education, the school today is more than ever required to make every effort to educate a man who is able to think constructively sound, with the knowledge and basic skills, which enable him to achieve smart fit with the nature of his time, and the characteristics of the environment Around it, and the rapid and successive changes and developments (Faqawi, 2009). Learning is a prerequisite for human adaptation to the environment in which he lives.It is a continuous learning process from birth until his death.He learns how to maintain his safety and life, how to organize his time, and choose his responses, and does not depend on one stage, the individual remains in a continuous learning process throughout his life., 2016).

Mekheimer (2011) investigated the impact of using video on learning English as a foreign language, and aimed to measure the benefits of listening, speaking, reading and writing skills using data from a yearlong experience. The results of the study showed that realistic videos that promote satisfactory assimilation and that are integrated in teaching language skills are a valuable approach to language teaching. Students were more active in the experimental group and Unlike the control group, the videos encouraged discussions between the teacher and students and the students themselves, encouraged students to continue writing, and the use of vocabulary, and improved the students' skills in the experimental group in listening, speaking, reading and writing. El-Borai (2013) conducted a study aimed at detecting the effectiveness of a computerized program for the treatment of reading difficulties among third graders. The presence of the effect was significant in the total score of the test, which indicates that the program has significantly affected student achievement. Soman (2014) conducted a study aimed at identifying the impact of enrollment in kindergarten or not on the development of reading and writing skills of lower secondary school students in Um Habiba Basic School in Jordan.The results showed that there are statistically significant differences between the average grades of female students. Hassan (2016) conducted a study aimed at verifying the effectiveness of a program based on the use of self-organized learning strategies to develop reading and writing skills in a sample of basic education pupils. The study concluded that there are statistically significant differences between the mean scores of the experimental group and the control group in reading skills in telemetry. In favor of the experimental group, there are statistically significant differences between the average scores of the experimental group and the control in writing skills in the telemetry. For the experimental group, there are no statistically significant differences between males and females in the experimental group in the distance measurement. $Z$ for reading skills, there are no statistically significant differences between males and females in the experimental group in the telemetric writing skills differences. 
Comment on previous studies:

A review of previous studies shows that this study is similar to previous studies in terms of detecting literacy skills and relying on the quasi-experimental approach.

This study differs in the selection of its sample from the first grade students, as most of the previous studies occur in the sample of students of different ages.

But it is characterized by the impact of computerized educational software in the achievement of the first grade students in learning Arabic in Jordan, a study - within the limits of science researcher - not addressed locally.

Based on the previous review, this study revealed the impact of computerized educational software on the achievement of the third grade students in learning Arabic in Jordan.

\section{The Study Problem}

The success of the educational learning process in teaching depends on many factors, including the curriculum and physical resources required for the teaching process. Since teacher behavior and teaching practices are influenced by the extent to which they understand the nature and structure of science, researchers are interested in studying the level of teachers' understanding of the nature of science and its impact on their educational behavior. This means that teaching is far from achieving some of the desired teaching and pedagogical goals, including helping students acquire the appropriate scientific knowledge and skills that enable them to accomplish the tasks assigned to them efficiently and well, and prepare them to be able to solve the problems that face them in their daily lives.

Because students can face many burdens and variables in society, the ability to learn is one of the basic requirements in the daily life of the individual, in order to be able to meet the requirements of the times.

Hence the recent trend in employing modern teaching methods in the educational learning process and investing them to develop higher scientific and intellectual skills of students and increase their scientific skills, the most important of which is the use of educational software (Mahasneh, 2015). In addition to the need to prepare students with the skills and experience to deal with the data of the times and challenges and employ technological innovations and invest their potential in the field of education. It requires identifying the possibility of using them in educational institutions in order to achieve the trends related to the preparation of individuals capable of dealing with the variables of this era (the customer, 2015).

For the scarcity of studies, especially Arabic researcher felt the need to study the impact of computerized educational software in the achievement of third grade students in learning Arabic in Jordan.

In light of the above, this study attempts to answer the following question:

- There is no statistically significant difference at the level of $(\geq 0.05$ in the achievement of the third grade students in learning Arabic in Jordan due to the method of teaching (the use of computerized educational software, the normal method)?

\section{Objectives of the Study}

This study aims to:

- Investigating the impact of computerized educational software on the achievement of third grade students in learning Arabic in Jordan.

\section{The Importance of Studying:}

This study is in line with the scientific and technological changes that have made a qualitative leap in the educational learning process, where the learner is considered the center of the educational learning process. Modern developed curricula focus on the development of thinking among students and the transition from the usual method to the most modern method. Learning skills through computerization of curricula in general, and Arabic language curriculum in particular. The importance of the study is summarized as follows:

1. May contribute to educating teachers the importance of using the Arabic language curriculum.

2. This study takes its importance from being one of the scientific researches complementary to human knowledge in the subject of using the computerized curriculum.

3. May be useful in assisting decision makers and educational planners working in the field of curriculum development and the use of technology in education.

4. This study opens the way for further field studies on the impact of computerized educational software in different subjects. 


\section{Terminology of Study}

This study includes a number of terms that can be defined as follows:

- Instructional Software: Defined by resourceful and Mari (2011) as a series of several points, designed with great care, to lead the student to master a subject with the least amount of errors. The researcher defines them procedurally as an educational material designed, developed and programmed by the researcher, using Dream Weaver () and pages (HTML) where they were used and applied to teach the third basic students.

- Dream Weaver: A special program for the design of web pages that create dynamic web pages programming DHTML and supports the concept of group patterns aggregation Cascading Style Sheets (CSS) in addition to adding layers and control behaviors Javascript JAVA SCRIPT and features to facilitate the management of the site where it includes the possibility of using the file transfer protocol with the possibility View the pages of the site as a visual diagram and the possibility of examining the links between the pages (ovaries, Obaisat, Qanbar, 2012).

Reading: Al-Darawsheh (2007: 91) defined it as a "process that links the language of speech and written symbols and includes the meaning and the symbol indicating the pronunciation". The researcher defines them procedurally as the process of converting written or printed symbols into meaningful sounds while understanding and recognizing the significance of these symbols Measured by the degree obtained by the student on the test.

Writing: Abed defined it as a re-encoding of spoken language in a linear form on paper, through forms that are related to each other, according to a well-known system that was once used by the language owners, in order to convey the writer's thoughts, opinions, and feelings to others (Abed, 2013: 19). It is procedurally defined as the ability of students to convert audible sounds into meaningful written or typed symbols, measured by the degree to which the student receives the test.

Paper Curriculum: The Arabic language curriculum written between the third grade textbooks, which the Jordanian Ministry of Education decided to teach in all schools of the Hashemite Kingdom of Jordan. In it, the teacher plays the main role in presenting content to students through lecture and explaining scientific concepts using the board, textbook, and some simple teaching aids. My unit (my family and my school) was selected from the paper curriculum.

Third grade students: They are students whose age ranges from 6-7 years old.

\section{Study Limits and Limitations}

In disseminating the results of this study, the following will be considered:

- This study is limited to the teaching of my family and my school from the computerized and written Arabic language textbook for the third year of basic reading and writing skills.

- This study is limited to a sample of the third grade students in the University of Jordan's Mixed Primary School of the Directorate of Education of the University Brigade in the first semester of 2018/2019.

- The validity of the results of this study depends on the sincerity of the tools used in it.

\section{Method and Procedures}

\subsection{Methodology of the Study}

In this study, the researcher used the quasi-experimental method to study human phenomena as it is unchanged, to investigate the effect of computerized educational software on the achievement of the third grade students in learning Arabic in Jordan, which is based on the selection of two divisions and divided into two groups: The usual method, the experimental group is subject to a computerized educational program.

\subsection{Study Personnel}

The study population consisted of third grade students at the University of Jordan School who are studying Arabic language for the academic year 2018-2019. The sample of the study consisted of two sections chosen intentionally from university students, one of which represents the experimental group of (25) students, and taught the Arabic language through (computerized educational software), and the other control group (25) students, and study the same material in the usual way. 


\subsection{Study Tools}

The following tools are developed to achieve the objectives of the study:

The first tool: achievement test:

To achieve the objectives of the study, an achievement test was constructed from the Arabic language textbook for the third grade students during the first semester of the academic year 2018-2019. The content was analyzed according to the specifications and objectives table, then the test paragraphs were formulated, taking into account Bloom's cognitive levels in agreement with a school. Subject.

Behavioral objectives were developed and formulated, and a material was developed to suit the use of computerized educational software in teaching. The total number of classes was 12 over the course of 4 weeks, and the educational material was developed to suit the proposed educational activities of the teaching method, while adhering to the curriculum content, where educational activities were prepared for the teaching of the unit, using the computerized educational software method and includes instructional videos designed Through the pages of (HTML) and Dream Weaver), and educational videos through YouTube, and images and written texts and worksheets because of their effective role in enriching learning. And Power Point slides, where various presentations were prepared to present the material in an exciting and engaging way.

\section{Validity and Stability of the Test:}

To verify the authenticity of the test, it was presented in its preliminary form to a group of 10 arbitrators with competence in curriculum and teaching, teaching technology, measurement and evaluation, and the Faculty of Arts at the University of Jordan. To ensure the stability of the test, the method of testing and retesting was used so that the final sample was applied to a sample of (25) third grade students who study Arabic language from outside the study sample, where they share the same characteristics of the study sample as the conditions, capabilities and physical facilities provided. The coefficient of stability (stability) was calculated for the academic achievement test and was equal to (83). According to the difficulty and discrimination coefficient of the test paragraphs, the difficulty coefficients on most of the test paragraphs were suitable, ranging from ( 0.30 0.65). These ratios are acceptable for the purposes of the study. As for the coefficient of discrimination of the paragraphs ranged from (33) to (63), and the paragraphs are generally distinct, meaning acceptable for the purposes of the study has been modified weak paragraphs in terms of discrimination. The coherence coefficient (persistence) using the Alpha Cronbach equation was (.84) and is acceptable for the purposes of the study. Table 1 illustrates this.

Table 1 . The results of the stability factors for the academic achievement test

\begin{tabular}{cccc}
\hline Achievement test & $\begin{array}{c}\text { Number of paragraphs } \\
\text { Stability coefficient } \\
\text { (App and re-app) for } \\
\text { testing }\end{array}$ & $\begin{array}{c}\text { Coefficient of internal } \\
\text { consistency } \\
\text { (Cronbach Alpha) }\end{array}$ \\
\cline { 2 - 4 }
\end{tabular}

\section{Study design}

EG : $01 \quad \mathrm{X} \quad 01$

CG : $01 \quad 01$

EG refers to the experimental group to be studied using computerized educational software, CG refers to the control group to be studied in the normal way, O1 refers to the achievement test scale (before, after), and X refers to the method of teaching using computerized educational software.

\section{Statistical Processing}

This study adopted the appropriate statistical methods obtained from the analysis of data, the use of descriptive and inferential statistical methods of arithmetic mean and standard deviation, and the analysis of the associated mono-variance (ANCOVA) to control the tribal differences from the measurement of study variables, and to find out the difference between the average performance of the experimental and control groups on the post-test.

\section{Results}

The results of the study, which aimed to find out the impact of computerized educational software on the achievement of the third grade students in learning Arabic in Jordan, were clarified according to the study questions as follows. 
Question 1: There is no statistically significant difference at the level of (5 في 0.05 in the achievement of the third grade students in learning Arabic language in Jordan due to the teaching method (using computerized educational software, the normal method)?

To answer this question, arithmetic averages and standard deviations of the control group and experimental group scores were calculated on the post-tribal achievement test and an associated ANCOVA was performed to detect the effect of the use of computerized educational software, as shown in tables $(2,3)$.

Table 2. Arithmetic averages and standard deviations, for the degrees of study members on the test before and after the academic achievement (total score) according to the variable of teaching method

\begin{tabular}{cccccc}
\hline \multirow{2}{*}{ The group } & \multicolumn{2}{c}{ Pre-test } & \multicolumn{2}{c}{ Post test } & \multirow{2}{*}{ The number } \\
\cline { 2 - 5 } & The mean & Standard deviation & The mean & Standard deviation & \\
\hline Experimental group & 22.25 & 3.695 & 28.47 & 2.236 & 25 \\
Control group & 21.27 & 2.857 & 23.21 & 4.152 & 25 \\
Total & 21.76 & 3.308 & 25.84 & 4.068 & 50 \\
\hline
\end{tabular}

Table 2 shows that the average scores of the experimental group students who studied using computerized educational software on the total score reached (28.47). The standard scores of the control group students who studied in the normal way on the total score were (23.21). The standard deviation (4.152), where there are apparent differences in the averages between the two groups for the experimental group that studied the Arabic language using computerized educational software, such as Bataineh study (2010), which aimed to know the impact of video use on the non-linguistic competence of English language learners in universities The Mekheimer study (2011), which aimed to find out the impact of using video on learning English as a foreign language, aimed to measure the benefits it brings in listening, speaking, reading and writing skills using data from a yearlong experience.

To find out whether there were statistically significant differences at the level of significance $(50.05)$ ), an associated ANCOVA was performed, as shown in Table (3).

Table 3. Results of Single Variance Analysis Associated with Examination of Differences in the Average Scores on the Post-Achievement Test

\begin{tabular}{cccccc}
\hline $\begin{array}{c}\text { Contrast } \\
\text { sources }\end{array}$ & Total squares & $\begin{array}{c}\text { Degrees of } \\
\text { freedom }\end{array}$ & Average squares & Values $F$ & Statistical significance \\
\hline $\begin{array}{c}\text { The associated } \\
\text { variable }\end{array}$ & 41.250 & 1 & 41.250 & 3.797 & 047. \\
$\begin{array}{c}\text { (Tribal } \\
\text { measurement) } \\
\begin{array}{c}\text { Teaching } \\
\text { method }\end{array}\end{array}$ & 281.926 & 1 & 281.926 & 27.618 & 000. \\
The error & 604.563 & 47 & 10.606 & \\
\hline The & 49 & & \\
\hline
\end{tabular}

Table (3) shows that there is a statistically significant difference at the mean level ( $\geq 0.05$ بين) between the mean of the post-achievement scores due to the variable of teaching method for the experimental group studied using computerized educational software, and therefore rejects the first zero hypothesis (there is no statistically significant difference between The average grades of students of both groups, experimental taught using computerized educational software, and control that is taught in the normal way in the achievement of the Arabic language, and this refers to the effectiveness of the use of computerized educational software in teaching third grade students.

Eta Square was calculated to determine the effect of teaching method on the academic achievement of the third grade students, and it was found that the size of the effect was large as the value of Eta Square is (0.724), that is, the method of teaching explains (72.4\%). (27.6\%) is not explained due to other factors. It indicates that there is a significant impact on the academic achievement of the Arabic language in the third grade students attributed to the method of teaching using computerized educational software.

This finding can be attributed to the study's advantages because the educational computing software has many advantages that are expected to serve the students' learning and contribute to their improvement, such as: This type of learning allows the learner to review his teaching material and study it once without feeling bored. At the 
time he wants and in the place he wants and this overall increases his motivation for learning, which increases his direct academic achievement, and that the method of learning through computerized educational software is a new way for students, which has aroused their interest and increased the motivation of learning to them, where this program is based on D C between abstract theoretical knowledge and practical application of the concrete, which provides the colors and images and animations and sounds and these things may give a greater educational impact than written words and enable the student to use the linguistic knowledge in all walks of life also enables the student to consolidate those linguistic concepts in the mind of the student, which increases In his educational attainment.

This corresponds to the epistemological theory of multimedia learning, which assumes that the human information processing system has a dual channel of processing - a visual-graphic channel and an audio-verbal channel - and that effective learning requires a consistent set of cognitive processors during learning. These are the five steps in multimedia learning: selecting appropriate words from audible text, selecting appropriate images from animation, coordinating selected words in coherent verbal representation, coordinating selected images in coherent visual representation, and combining visual and verbal representations with prior knowledge (Mayer, 2001).

It can be attributed to the way of learning through computerized educational software rich in multiple examples and exercises and this diversity may serve to consolidate the learning of students as students can learn during the use of computerized educational software to see more than one example, and have the opportunity to solve many of the exercises Related to the subject of study in the textbook, which facilitates these concepts and absorbed and deepened in their knowledge structure and this may increase their educational attainment.

This result can also be attributed to the various educational applications provided by the computerized educational software that may contribute to improving students 'academic achievement. The technical applications contained in the software may contribute to improving students' academic achievement by deepening understanding using images, audio and video. To applications that provide access to enriched sites from libraries and scientific encyclopedias through links included in the designed lessons.

During the course of the study, the researcher noted that changing the classroom environment and departing from the ordinary in explaining the lessons showed students' enthusiasm, love of exploration and the search for information, rather than receiving and preserving it.

In addition to questions and self-tests and the feedback provided by the information that students have addressed during the research, and assess their performance and identify and review their mistakes, has contributed to the understanding of information and entrenched in their mental structure, which has increased their academic achievement.

As a result of the computerized curriculum based on the multiple senses used in the educational learning process, it helps to take into account the individual differences between students, thus providing multiple learning opportunities so that each student learns according to their learning style, and the use of more than one sense in the educational learning process helps to stabilize information in memory Further, when using a paper-based curriculum, the learner depends on learning only one sense.

This result can be attributed to the computerized curriculum provided by an effective electronic environment so that the learning environment is centered on the learner, and all the knowledge and scientific knowledge the student possesses depends on the quality of experience he is going through. The electronic environment is suitable for understanding and acquiring scientific concepts, and the computerized curriculum has helped convince students of the truthfulness and value of concepts, thus overcoming the conceptual difficulties they face, which helps to make effective learning less likely to be forgotten.

The computerized curriculum provides multiple experiences so that these experiences are closer to the real experiences, and is based on visual activities, which is a base that touches the needs of students in the second grade basic stage, which will achieve deeper learning and greater impact, as it works to fragment the educational experiences and present them in an easy to understand This enables students to store experiences in memory at varying levels according to the desire to select, for example, the images and sounds available to the computerized curriculum. In addition, the use of the computerized curriculum provides access to all activities by voice, image and movement compared to the members of the control group who did not have access to all activities due to the difficulty of application within the classroom, such as the activity of the properties of the invasive material where it is difficult to apply a visual activity shows that the invasive material has a fixed shape and size Not fixed. The exposure of the members of the experimental group to a greater amount of experience compared to the members of the control group helped to acquire scientific concepts. The computerized 
curriculum also provides the possibility to repeat the educational practices whenever the learner wants because of the availability of the computerized curriculum and activities on the Internet all the time, where each student can refer to activities whenever he wants, and the student can test himself through the enrichment activities on the network Ideoev.

In addition, the computerized curriculum requires the use of computers, and the use of computers in the educational learning process helps to solve many of the problems faced by teachers when using the paper curriculum, including the overcrowding of students in classrooms, which is an obstacle to the possession of most students of the concepts and skills, and provide equal opportunities for all students, Each student learns according to his / her abilities and abilities and helps to attract the attention of the students thus ensuring that the information has been provided to each student (Ashteeh and Olayan, 2010).

The computerized curriculum was built on the foundations that ensure the integrity of the scientific concept formation, survival and retention, contrary to the usual way that may lead to the unsafe composition of the scientific concept, because the concept is incomplete or confused with converging scientific concepts as a result of its reliance on memorization and memorization.

In the light of the above findings, the following conclusions can be drawn:

The presence of a significant impact on the academic achievement of the Arabic language for third grade students attributed to the variable method of teaching, for the benefit of the experimental group that studied computerized educational software. This indicates the impact of the use of computerized educational software in teaching Arabic language to third grade students.

\section{Recommendations and Suggestions}

In the light of the results of the study, the researcher makes the following recommendations and suggestions:

- Dissemination of the experience of using a computerized educational software that was applied to the students of the Arabic language on various subjects.

- Benefit from the positive impact of the use of computerized educational software in the achievement of students.

- Conducting new studies with different designs and measurement tools to investigate the impact of using computerized educational software in a variety of subjects and levels of study.

\section{References}

Abed, Walid Nady (2013). The effectiveness of a program using some strategies of task analysis in the acquisition of reading comprehension skills for children with learning disabilities, Master Thesis, Institute of Educational Studies, Cairo University.

Abu Ghazal, Muawiya \& Khadir, Raed (2016). Motivation of reading \& its relation to the social class environment among middle school students in Irbid governorate. Jordan Journal of Educational Sciences, 12(3), 375- 396.

Abu Hassan, Salam (2007), e-learning system. Teacher's Message: Ministry of Education, 45(3), 60-63.

Al-Enezi, Fatima (2011). Educational Innovation \& E-Learning, (i 1), Amman: Dar Al-Raya for Publishing \& Distribution.

Al-Lidawi, Manal (2010). the degree of the acquisition of the ninth grade students in the first Amman Directorate of Life Skills through the computerized mathematics curriculum. Unpublished Master Thesis, University of Jordan, Amman, Jordan.

Bataineh, A. (2010). The Effect of Using Videos on University EFL Learners' Nonverbal Competence, Journal of Islamic University, (2), 1295-1322.

Boerum,L.J. (2000). Developing Portfolios with Learning disabled Students, Reading \& Writing Quarterly, 16, 23-211.https://doi.org/10.1080/105735600406724

Customer, Safe (2015). The Effect of Teaching Using Electronic Models on the Achievement of Computer Skills at the University of Jordan \& the Development of Self-Learning \& Social Communication Skills, Unpublished PhD Thesis, University of Jordan, Amman, Jordan.

Darawsheh, Muhammad (2007). The impact of an educational program based on constructive learning theory on the acquisition of literacy skills for students of slow reading in the initial stage in Jordan. Unpublished thesis, Amman Arab University for Higher Education: Jordan. 
De Caso, Ana Maria \& Garcia, Jesus-Nicasio, (2004). Effects of a Motivational Intervention for Improving the Writing of Children with Learning Disabilities. Learning Disability Quarterly, 27(3), 59-141.https://doi.org/10.2307/1593665

Edmunds, K. M. \& Bauserman, K. L. (2014). What Teachers Can Teach About Reading Motivation Through Conversations with Children, The Reading Teacher, 59, 414-424.https://doi.org/10.1598/RT.59.5.1

El-Borai, Abdullah (2013). The effectiveness of a computerized program for the treatment of reading difficulties among third grade students. Unpublished Master Thesis, Islamic University, Gaza.

Eshtayoh, Fawzi Fayez \& Alian, Ribhi Mustafa (2010). Educational Technology Theory \& Practice, (i 1), Amman: Dar Safaa for Publishing \& Distribution.

Faqawi, Jamal (2009). The Effectiveness of a Proposed Program in the Treatment of Spelling Learning Difficulties among Seventh Grade Students in Khan Yunis Governorate. Unpublished Master Thesis, Islamic University, Gaza.

Habayeb, Ali (2010). Difficulties in learning to read \& write from the point of view of first grade teachers. Journal of Al-Azhar University in Gaza, 3(1), 1-34.

Hassan, Mee (2016). The effectiveness of a program based on the use of self-organized learning strategies to develop literacy skills among a sample of basic education students, unpublished Master Thesis, Ain Shams University, Egypt.

Liou, Pey-Yan, (2010). Cross-National Comparisons of the Association Between Student Motivation for Learning Mathematics \& Achievement Linked with School Contexts. Ph.D, Unpublished Dissertation University of Minnesota

Mahasneh, Omar (2015). The effect of using integrated learning on the achievement of fifth grade students in the curriculum of vocational education, Journal of University of Jordan Studies, 42(2), 681-692. https://doi.org/10.12816/0017392

Mayer, R.E. (2001). Multimedia Learning, Cambridge, UK: Cambridge University Press.

Mekheimer, M. (2011). The Impact of Using Videos on Whole Language Learning in EFL Context, Arab World English Journal (AWEJ), 2(2), 5-39.

Merhi, Tawfiq Ahmad \& Al-Hailah, Mohammed Mahmoud (2011). Educational Technology between Theory \& Practice, Amman: Dar Al-Maysara.

Nashawati, Abdul Majeed (2010). Educational Psychology. I (3), Amman: Al-Resala Foundation.

Peelo,M (1994). Helping Students with Study Problems. Buckingham, The Society for Research in to Higher Education \& Open University press.

Perrin, D. (2007). Technology \& Change, International Journal of Instructional Technology \& Distance Learning, 4(9), 11-22.

Putman, Michael \& Walker, Carolyn. (2010). Motivating Children to Read \& Write: Using Informal Learning Environments as Contexts for Literacy Instruction. Journal of Research in Childhood Education, 24, 140-151.https://doi.org/10.1080/02568541003635243

Savas, P. (2012). Micro-teaching Videos in EFL Teacher Education Methodology Courses: Tools to Enhance English Proficiency \& Teachers Skills among Trainees, Procedia-Social \& Behavioral Sciences, 55, 730-738.https://doi.org/10.1016/j.sbspro.2012.09.558

Sharab, Zainat Abdul Rauf (2013). The effectiveness of using self-learning strategy to improve the listening skill of secondary school students in English. Journal of Reading \& Knowledge: Egypt, 13(8), 61-84.

Shboul, Muhannad Anwar \& Olayan, Ribhi Mustafa (2014). e-learning, (i 1), Oman: Dar Safa for publication \& distribution.

Suman, Ahmad (2014). The impact of enrollment in kindergarten or not on the development of reading \& writing skills of students at the lower basic level at Um Habiba Elementary School in Jordan. An-Najah University Journal for Research, 28(4). 791-834.

The Ovaries, Wissam \& Obeisat, Farhan \& Qanbar, Isa (2012). Web Design using Dream Weaver, Dar Zamzam \& Amman, Jordan. 
Zaytoun, Ayesh (2008). Methods of Teaching Science, (I 1), Amman: Dar Al-Shorouk for Publishing \& Distribution.

Zaytoun, Ayesh (2010). Contemporary Trends in Science Curricula \& Teaching, (I 1), Amman: Dar Al-Shorouk for Publishing \& Distribution.

Zoubi, Elham (2010). Computer in Education: Achievements \& Aspirations. Teacher's Message: Ministry of Education, 49(3), 67-67.

\section{Copyrights}

Copyright for this article is retained by the author(s), with first publication rights granted to the journal.

This is an open-access article distributed under the terms and conditions of the Creative Commons Attribution license (http://creativecommons.org/licenses/by/4.0/). 